\title{
University of Michigan-Dearborn
}

\section{Influence of High Pressure EGR System in reducing Nitrogen Oxide}

Akash Ladha

\section{ABSTRACT}

High Pressure Exhaust gas recirculation (HPL EGR) is an emission control technology which can significantly reduce nitrogen oxide (NOx) emission in gasoline and diesel engines, from light-duty engines through medium- and heavy-duty engine applications and right up to low-speed, two-stroke marine engines.

While reducing NOx is the most common reason for applying HPL EGR to modern commercial diesel engines, its potential application also extents to other purposes like imparting knock resistance and reducing the need for high load fuel enrichment in SI engines, aiding vaporization of liquid fuels and as an enabler for closed cycle diesel engines.

This paper will explore the high pressure EGR design, cooled and uncooled EGR, combustion and emission impacts of EGR, advantages and disadvantages of high pressure EGR, influence on PM and $\mathrm{HC}$ emissions and future trends.

Keywords Exhaust gas recirculation EGR, High Pressure, NOx emission, NOx reduction, Selective catalytic reduction SCR

\section{INTRODUCTION}

Road transport is the largest contributor to NOx emissions. Nitrogen oxides in the atmosphere contribute to the destruction of ozone in the stratosphere and to global warming to a large extent. Increasingly stringent NOx emissions regulations are being applied and some emerging technologies are being researched for meeting stricter emissions regulations.

Various methods like SCR (selective catalytic reduction), Exhaust Gas Recirculation (EGR) , Three-way Catalysts are used to reduce NOx

$E G R$ is an engine management strategy to control NOx in which a part of engine's exhaust gas is returned to its combustion chambers via the inlet system. It is the principle technique whichused to control NOx emissions. A basic conceptual schematic of an exhaust gas recirculation system is shown in Fig. 1.

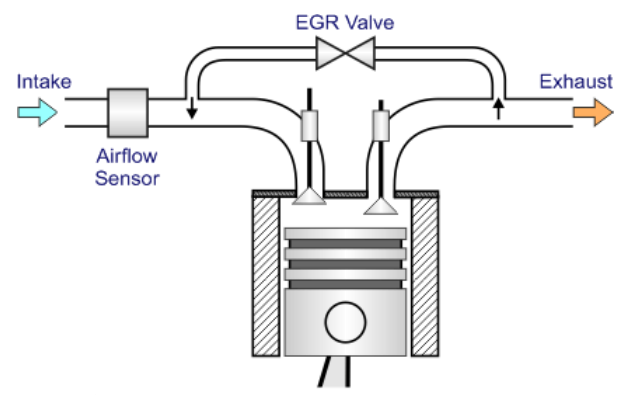

Figure 1 EGR layout [1]

This dilutes the $\mathrm{O} 2$ in the incoming air stream and provides inert gases to 
combustion acting as absorbents of combustion heat to reduce peak incylinder temperatures. The recycled exhaust gas is usually mixed with the fresh fuel-air mixture just below the throttle valve.

Since NOx is formed primarily when a mixture of oxygen and nitrogen is subjected to high temperature, the lower combustion chamber temperatures which caused by recirculating exhaust gas reduce the amount of NOx that the combustion process generates.

The exhaust gases which are reintroduced from HPL EGR systems will also contain near equilibrium concentrations of $\mathrm{CO}$ and NOx, the small fractions which areare initiatlly present in the combustion chamber inhibits the total net production of these and other pollutatnds when sampled on a time average.

EGR acts, at part load, as diluent in the unburned gas mixture which eventually reduces the peak burned gas temperatures and NOx formation rates. It is the total burned gas fraction in the unburned mixture in the cylinder that acts as a diluent. The burned gases are residual gases from the previous cycle and exhaust gas. Thereby, NOx is produced in a narrow band of high cylinder temperatures and pressures.

In a gasoline engine, this inert exhaust displaces some amount of combustible matter while in a diesel engine, the exhaust gas replaces some of the excess oxygen in the pre-combustion mixture.Most modern engines now run on EGR to meet emissions standards.

\section{COOLED EGR AND UNCOOLED EGR}

The Exhaust gas which is recirculated is normally cooled before returning it into the combustion chamber.

HPL EGR gas temperature is normally reduced by using the cold EGR coolant generated from a radiator and an electric coolant pump.

The results showed that with low temperature (LT) HPL EGR there was remarkable reduction in NOx at low load condition where we had low EGR flow. NOx is reduced by around $4 \%$ at NEDC 14 modal points. Also low temperature EGR can decrease NOx at the same PM emission.

In commercial applications, HPL EGR is often cooled and thus the intake manifold temperature rise may not be encountered.

Uncooled EGR can also adversely affect the Air / Fuel (A/F) ratio and thus increase the charge temperatures but they also help in improved combustion stability at lower loads, faster engine warm-up and also prevention of condensation in the intake manifold.

Cooling is important if EGR is used at higher engine loads to maximize the A/F ratio inorder to sustain good combustion efficiency and lower PM emissions.

Cooled HPL EGR increases the amount of EGR under same air-fuel ratio conditions, and decreases the NOx emission.

In LT HPL EGR, as coolant temperature is decreased, it can be expected that the amount of NOx reduction is also increased. But it will also cause EGR cooler fouling problems and higher 
unburned $\mathrm{HC}$. Therefore it is important to find out the relation between NOx reduction and LT HPL EGR coolant temperature.

In some of the light-duty diesel applications they incorporate features that allow uncooled HPL EGR to be used in some engine operating conditions. Exusing an EGR cooler bypass or dual loop systems where one loop is uncooled.

Fig 2 shows the coolant circuit concept for LT EGR comparing with base engine. In case of base engine, some part of engine coolant pass through EGR cooler by mechanical water pump and cooled down at radiator when thermostat valve opens. The EGR coolant circuit of LT EGR is separated from engine coolant line. It is driven by additional electric water pump, and can always cool down at radiator without passing the thermostat.

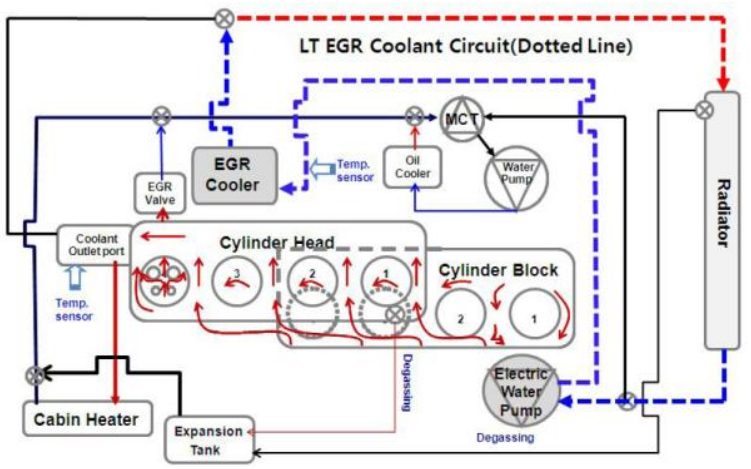

Figure 2- LT EGR coolant

LT EGR test is to measure intake and EGR gas temperature and emission with the change of LT EGR coolant temperature. LT EGR coolant temperature was varied from 95 to $55^{\circ} \mathrm{C}$ by $10^{\circ} \mathrm{C}$. The EGR cooler efficiency is defined as the ratio of the temperature difference between cooler gas inlet and outlet to temperature difference between cooler gas inlet and EGR coolant inlet.
The calculation equation for EGR rate and EGR cooling efficiency are given as follows.

EGR rate $=\frac{\left(\mathrm{CO} 2_{\text {intake }}-\mathrm{CO} 2_{\text {ambient }}\right)}{\left(\mathrm{CO} 2_{\text {exhaust }}-\mathrm{CO} 2_{\text {ambient }}\right)}$

EGR cooler efficiency

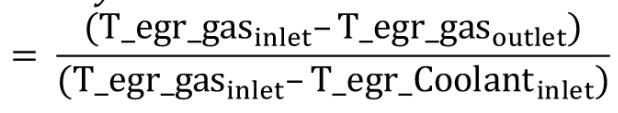

The inlet temperature of HPL EGR coolant of base engine has the increasing trend as the cycle time elapses. It is seen that LT EGR coolant temperature is lower by 20 to $50^{\circ} \mathrm{C}$, since th LT EGR coolant cools down by passing through radiator. From various simulation results and taking into consideration the EGR cooler fouling, it is good to operated at a minimum of LT EGR coolant temperature of $55^{\circ} \mathrm{C}$.

Fig 3 shows the HPL EGR cooler cooling efficiencies for cases having high and low NOx reduction rate. EGR cooler cooling efficiency for both cases is decreased as EGR coolant temperature decreases. But for the EGR cooling efficiency having EGR flow at $104 \mathrm{~kg} / \mathrm{h}$ and NOx reduction rate $3 \%$ is decreased more rapidly compared with that of EGR flow of $60 \mathrm{~kg} / \mathrm{h}$ and NOx reduction rate of $10 \%$. In case of having higher EGR flow, the EGR cooling efficiency becomes worse rapidly compared with the low EGR flow with decreasing EGR cooler coolant. This leads the difference of NOx reduction rate with respect to EGR flow. It is seen that, using LT EGR and having the EGR rate and main timing tuned, will decrease NOx by about $4 \%$ at same PM levels [2] 


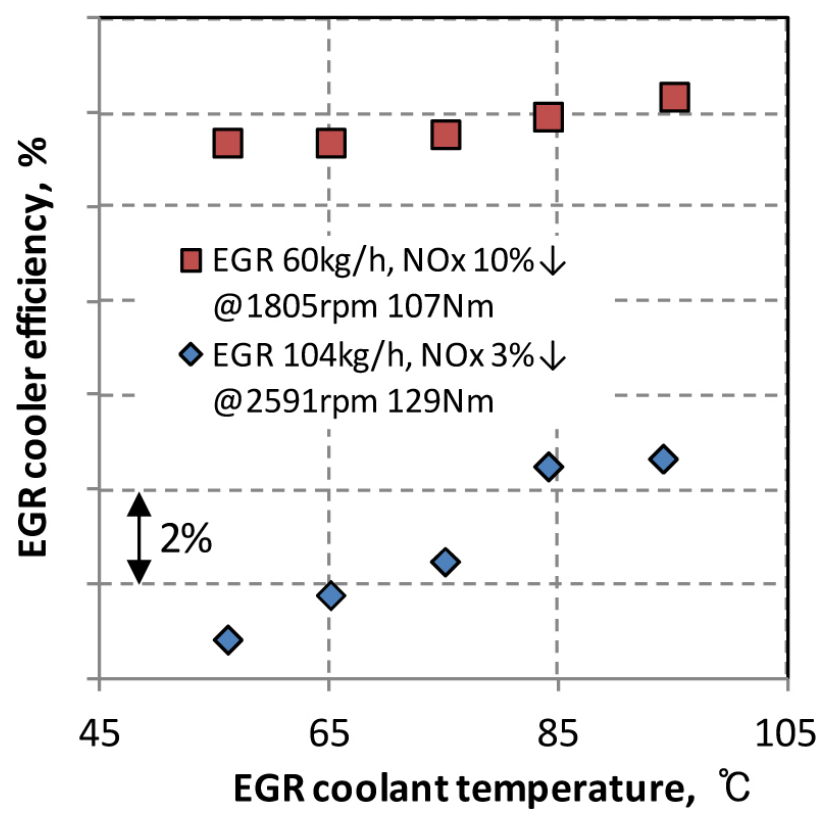

Figure 3- EGR cooler efficiencies at two cases of high and low EGR flow

\section{EFFECT OF EGR ON COMBUSTION AND EMISSIONS}

HPL EGR is the method to effectively reduce the NOx emission from a diesel exhaust. HPL EGR is used in light-duty application. In an EGR system, a portion of the engine's exhaust is recycled back into the engine's intake air system. NOx reduction using EGR is achieved in two ways. First, the oxygen concentration in the combustion mixture is reduced by diluting the intake air with the combustion products. Second, the peak combustion temperature is reduced by introducing the products of combustion such as $\mathrm{H} 2 \mathrm{O}$ and $\mathrm{CO} 2$ as heat absorbers. The effect of lower combustion temperature is reduction in NOx formation. HPL EGR has the effect of reducing $\mathrm{O} 2$ concentration and this gives a proportional reduction in the heat release per unit mass of mixture and also this lowers the rate of NOx formation. This provides an additional means for reducing the peak firing temperature. The reduction of oxygen also helps in delaying the Oxidation of atmospheric nitrogen. All these mechanisms result in lower NOx level. HPL EGR is especially applicable at part load conditions where the reduced $\mathrm{O} 2$ concentration is less likely to increase soot formation. At full load conditions the airfuel ratio is much less and addition of HPL EGR leads to excessive soot formation. Inorder to avoid the excessive formation of soot at full load, one has to limit the use of EGR [3]

The most important factor which contributes to the NOx reduction effect by EGR is the peak combustion flame temperature. The effects leading to the lower peak temperature can be broken down into (1) Dilution effect, (2) Added Mass effect, (3) Thermal effect (4) Chemical effect.

The understanding of each of these effects is useful to better understand the overall impact of charge dilution with EGR. Again, separating the impact of these effects is very difficult and requires careful planning of engine experiments. The working definitions of these effects used by different reserachers is not consistent. Also in some of the works these effects are combined together without stating anything explicitly.

A significant amount of work was carried out by Ladommatos and his colleagues in the late 1990s to clarify the effect of HPL EGR on diesel combustion and emissions. Their experiments were designed to separate the impacts of the 
different effects mentioned above. The definitions of the different effects are based on this work.

1. Dilution Effect - The dilution effect describes the flame temperature and NOx emission reductions which result solely from a reduction in the mass of oxygen / molar fraction when some of the oxygen present in the fresh intake air charge is displaced by an inert gas. This is the most significant contributor to NOx reductions with HPL EGR in diesel engines. For a given quantity of fuel, a fixed amount of oxygen is required to complete combustion no matter what the level of EGR is. Since the mass/molar fraction of oxygen is lower with EGR, the flame must broaden to entrain the requisite oxygen. An increased proportion of non-oxygen molecules in the broadened flame zone will absorb the heat from the flame and will eventually lower the flame temperature.

Adding EGR to the intake air flow will also affect the average properties such as the specific heat capacity and molecular mass of the intake charge, possibly introducing other effects. It should be noted that the impact of HPL EGR on the availability of oxygen for the chemical reactions responsible for NOx formation is minor.

In experimental works, intended to isolate the dilution effect, it is necessary to use an inert diluent which has a specific heat capacity matched to that of air. This can be achieved by using a mixture of Argon and Nitrogen. The mass flow of intake charge and fuel must also be the same for the experiments with and without the charge dilution.
2. Added-Mass Effect - Adding a diluent to the intake charge results in an increased mass flow rate. With this there is an additional effect that is introduced. This added flow has an additional heat capacity due to its mass and can be referred to as the added-mass effect. This is different from the thermal effect resulting from the differences in specific heat capacity. The thermal effect works in conjunction with the added-mass effect to change the heat absorption capacity of the non-reacting gases in the combustion chamber.

3. Thermal Effect - HPL EGR contains significant amounts of $\mathrm{CO} 2$ and water, both of which have significantly higher specific heat capacities than air. The thermal effect is due to the increase in the average specific heat capacity of the gases that are in the combustion zone.The intake air dilution with EGR can simultaneously introduce the dilution and thermal effects.

4. Chemical Effect - Some of the diluent gases may dissociate or might actively participate in chemical reactions during the combustion process. The chemical effect could lead to a change in the combustion temperature due to the chemical reactions of the gases introduced through HPL EGR. For ex, heat is consumed (i.e., temperature can decrease) during endothermic reactions such as the dissociation of $\mathrm{CO}_{2}$ and $\mathrm{H}_{2} \mathrm{O}$.

One way to isolate the chemical effect is to replace the nitrogen in the air with Argon while the diluent is present. This will maintain a constant average specific heat capacity and the oxygen concentration in the intake charge 
relative to the undiluted case and maintaining constant inlet charge and fuel mass flows. This will avoid interference from the thermal and dilution effects. Fig 4 illustrates the effect of

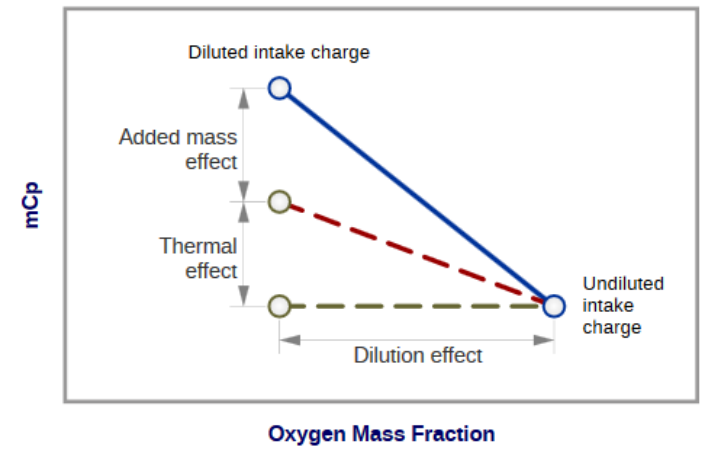

Figure 4 - Conceptual view of EGR effects

charge dilution on the oxygen mass fraction and the product of intake charge mass and heat capacity $\left(\mathrm{mC}_{\mathrm{p}}\right)$ that might occur in an engine with EGR. All effects might occur simultaneously making it difficult to determine which is more important. The dilution effect only accounts for the reduction in oxygen mass fraction while the thermal effect for the differences in average specific heat capacity and the added-mass effect for differences in the intake charge mass. The chemical effect may also be present.

Fig 5 shows the relative NOx reductions for various effects like thermal, chemical, and dilution effects in isolation and also for the combined NOx reduction for these three effects when charge dilution is with pure $\mathrm{CO}_{2}$. Intake charge and fuel mass flows were fixed so there is no "addedmass" effect. It is apparent that most of the NOx reduction from $\mathrm{CO}_{2}$ is through the dilution effect with a small additional contribution from the chemical effect. The thermal effect was found to be insignificant at dilution levels up to $7 \%$ even though $\mathrm{CO}_{2}$ has a higher specific heat capacity than air $(1.24 \mathrm{~kJ} / \mathrm{kg}$ and $1.16 \mathrm{~kJ} / \mathrm{kg}$ at $1000 \mathrm{~K}$, respectively). This is because adding $6 \% \mathrm{CO}_{2}$, the amount present with $~ 50 \%$ EGR to air increases the specific heat capacity by less than $0.5 \%$. In the case of $\mathrm{CO}_{2}$, the chemical effect results in an additional reduction of flame temperature over and above that resulting from the dilution effect.

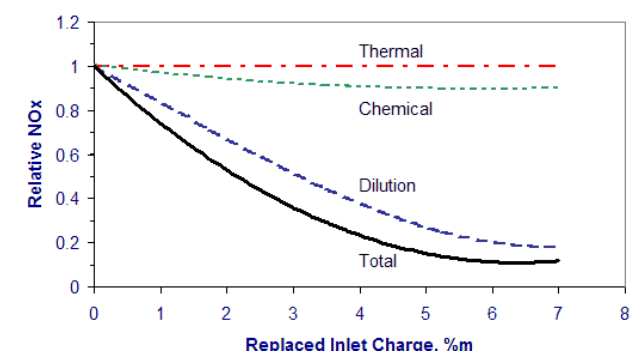

Figure 5 - EGR Effects with pure Co2 Dilution

Fig 6 shows the additional reduction in NOx when dilution results in additional mass in the intake charge. The baseline condition is the undiluted intake charge. The "oxygen replacement" condition has the same fuel mass flows and intake charge as the baseline but with some of the oxygen that is replaced by $\mathrm{CO}_{2}$. Reduction of NOx includes the combined chemical and dilution effects. The "added-mass" condition maintains the same intake air flow and fuel flow as the baseline condition but has an additional amount of $\mathrm{CO}_{2}$ introduced to the intake flow which increases the intake charge mass flow by $10 \%$. The oxygen concentration (\% mass) is the same as for the "oxygen replacement" condition to maintain the same dilution effect. It is seen that the additional heat capacity of the extra mass in the intake charge produces an additional reduction in NOx. [1] 


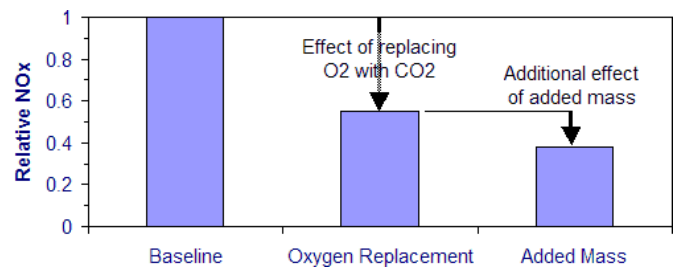

Figure 6 Effect of Adding Additional Mass to intake Charge

\section{COMBUSTION IMPACTS}

The main impact of the dilution effect is to reduce local flame temperatures. Lower flame temperatures provide a significant reduction in NOx formation in the flame zone. The reduction in temperature is due to the result of the changes in the flame zone that result from differences in oxygen fraction relative to the fraction of the "nonoxygen" gases. For ex. at 50\% EGR, a flame temperature reduction of about 100 $\mathrm{K}$ can occur.

Fig 7 shows a simplified representation of a diesel diffusion flame with and without EGR. The main reaction zone occurs in the region where the local oxygen to fuel ratio is essentially at stoichiometric $(\varphi \sim$ 1 ). As some of the oxygen in the inlet charge is displaced with other gases, more inert gas will be present in the combustion zone relative to oxygen and since the amount of fuel that is added will remain constant, the fuel will have to diffuse further and the shape and size of the flame will adjust to maintain the stoichiometric conditions in the flame zone. The added mass of non-reacting gases in the combustion zone absorbs heat and lowers the temperature. Others have visualized the broadening out of the diesel combustion flame with increased dilution.
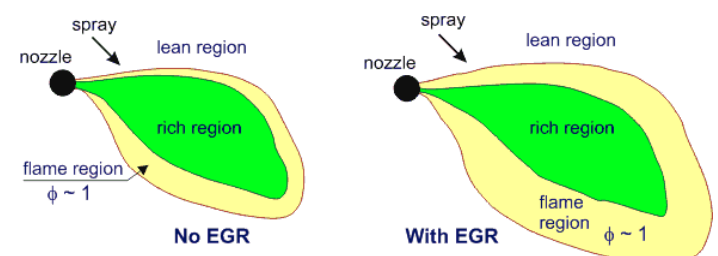

Figure 7-Diesel Diffusion Flame with and without EGR

It is seen that the important impact of the dilution effect is to lower the peak flame temperatures. The secondary and far less important effect is the reduction in the amount of oxygen available for the chemical reactions involved in NOx formation. The relative importance of these influences is shown in the Fig 8 and Table 1. Fig 8 shows there is a strong correlation between the observed peak flame temperature and the final NOx concentration at the exhaust, as a result of adding a non-reacting gas to the intake air to lower the oxygen concentration in the flame zone. As explained above, this non-reacting mass absorbs heat in the combustion zone and lowers the temperature.

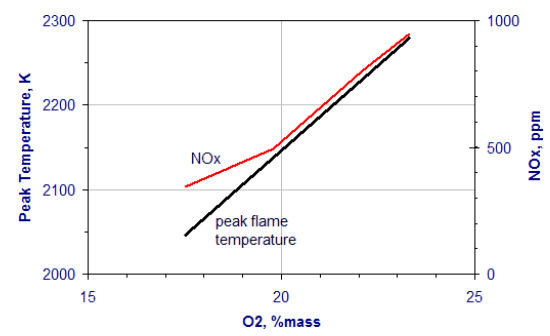

Figure 8-Correlation between NOx and Flame Temperature

\section{Table1}

Estimated NO Formation Rates relative to $23.3 \% \mathrm{O}_{2}$ Condition

\begin{tabular}{|l|l|l|l|l|}
\hline & & & $\mathbf{O}_{2}=\mathbf{2 3 . 3} \%$ & $\begin{array}{l}\mathrm{T}=2280 \\
\mathbf{K}\end{array}$ \\
\hline $\begin{array}{l}\mathbf{O}_{2}, \\
\%\end{array}$ & $\begin{array}{l}\text { Peak } \\
\text { Temp, } \\
\mathbf{K}\end{array}$ & $\mathrm{d}[\mathrm{NO}] / \mathrm{dt}$ & $\mathrm{d}[\mathrm{NO}] / \mathrm{dt}$ & $\mathrm{d}[\mathrm{NO}] / \mathrm{dt}$ \\
\hline 23.3 & 2280 & 1.00 & 1.00 & 1.00 \\
\hline 22.1 & 2220 & 0.44 & 0.45 & 0.97 \\
\hline
\end{tabular}




\begin{tabular}{|l|l|l|l|l|}
\hline 19.8 & 2160 & 0.18 & 0.19 & 0.92 \\
\hline 17.5 & 2035 & 0.02 & 0.03 & 0.87 \\
\hline
\end{tabular}

Table 1 demonstrates the impact of low availability of oxygen for chemical reactions for the data of Figure 8 is relatively insignificant. The first two columns show the mass concentration of oxygen and the peak flame temperatures for the different conditions. The third column shows the $\mathrm{NO}$ formation rate relative to the $23.3 \%(\mathrm{~m} / \mathrm{m}) \mathrm{O}_{2}$ condition estimated from [1]

(4) $\mathrm{d}[\mathrm{NO}] / \mathrm{dt}=\left[6 \cdot 10^{16} / \mathrm{T}^{0.5}\right] \times \exp (-$ $69090 / \mathrm{T}) \times\left[\mathrm{O}_{2}\right]^{0.5} \times\left[\mathrm{N}_{2}\right]$

The fourth column shows the relative NO formation rate at the temperatures in column 2 but with the oxygen concentration of $23.3 \%(\mathrm{~m} / \mathrm{m})$. Column five shows the relative NO formation rate at temperature of $2280 \mathrm{~K}$ but with the oxygen concentrations of column 1. By comparing the $\mathrm{NO}$ formation rate estimates in columns 3 with those in column 4 and 5 , it is seen that the impact of reduced oxygen availability for chemical reactions is almost negligible compared to the effect of temperature decrease resulting from the broadening of the diffusion flame.

Other combustion influences that are important for EGR include:

- The effect of HPL EGR is minimal on the fuel spray angle, injector tip penetration and fule automization

- With higher EGR rates the number of auto-ignition sites, as well as their size, increases.

- Flame luminosity is reduced.
- With its effect on both intake air and combustion temperatures, EGR also affects the exhaust gas temperatures. With uncooled EGR the exhaust temperature typically increases, especially at higher engine loads. However, in the case of cooled EGR, there is no general rule and the effect depends on the effectiveness of EGR cooling and other variables.

\section{EGR Operating Regions:}

In SI engines, HPL EGR is typically not used at high loads as it would reduce peak power output and also because it reduces the intake charge density. Also omitted at idle condition (low-speed, zero load) because it would cause unstable combustion, resulting in rough idle. A good advantage under light cruise conditions is that the HPL EGR valve cools the exhaust valves and increases the life span.

In modern diesel engines, the HPL EGR gas is cooled via heat exchanger that allows the passage of more mass of recirculated gas. Unlike SI engines, diesels have preference over by the need for a contiguous flamefront and since diesels always operate with excess air, they benefit from EGR rates as high as $50 \%$ (at idle, when there is otherwise a large excess of air) in controlling NOx emissions. Exhaust recirculated back can increase engine wear as carbon particulate wash past the rings and into the oil.

EGR does not lower throttling losses in diesel engines as they are unthrottled but it does for SI engines. Exhaust gas (largely carbon dioxide and water vapor) having higher specific heat than air helps to lower peak combustion temperatures. 
However, adding EGR to a diesel lowers the specific heat ratio of the combustion gases in the power stroke which eventually reduces the amount of power extracted by the piston.

The amount of HPL EGR should be controlled in a precise manner otherwise it results into adverse effects on engine performance, component life and other emissions. Compared to NOx and PM, the $\mathrm{HC}$ and $\mathrm{CO}$ emission limits are not expected to be an issue, because the engine out emissions is already very low. However, both combustion optimization and advanced emission control systems will be responsible in major reductions of both PM and NOx emissions required in the near future. [4]

\section{HPL EGR and soot formation :}

One of the challenges of applying EGR is the need to minimize or even eliminate unacceptable increases in PM emissions. A trade off between NOx and $\mathrm{PM}$ has to be considered when EGR is introduced

If the fuel burns at a higher temperature inside the cylinder, little soot is produced, but it produces a large amount of nitrogen oxide. At lower combustion temperatures, nitrogen oxide emissions are low, but the production of soot is high. EGR also tends to reduce the amount of fuel burned in the power stroke. This is evident by the increase in particulate emissions that corresponds to an increase in EGR.

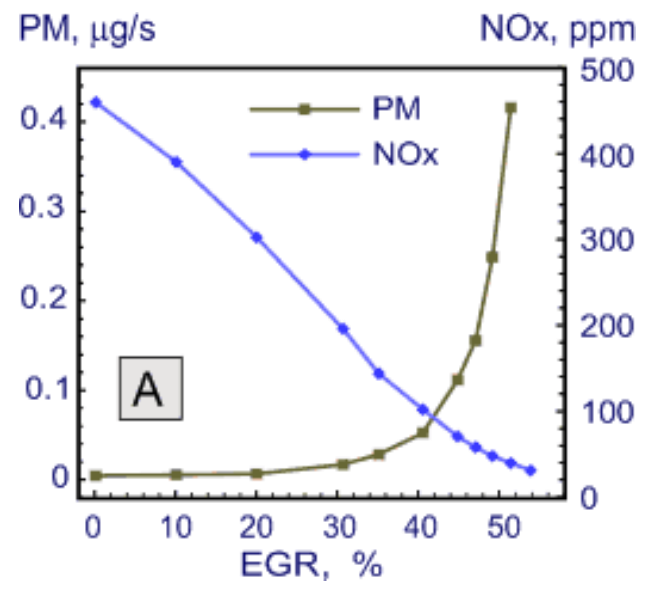

Figure 9 - PM vs NOx

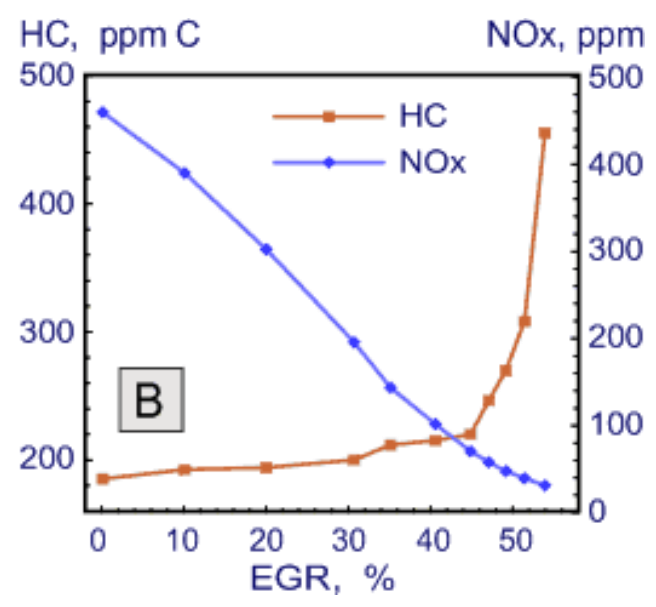

Figure 10- Nox vs HC

The soot increase with small amounts of EGR is primarily due to a decrease in the oxidation rate of soot in the later stages of the combustion process. In order to decrease the higher amounts of soot that are remaining at the end of the combustion process, changes to the combustion system are required. This is either to decrease soot formation and/or increase soot oxidation. Increased fuel injection pressure, injector nozzle design and combustion chamber design are some options for achieving these soot control measures when EGR is applied.

FOULING IN EGR COOLERS: 
Circulating EGR is one of the widely used method to reduce NOx emissions. This is usually done by heat exchanger or EGR cooler. However, they are subjected to severe fouling which decreases their thermal efficiency and drop it by 30\% within less time span. The fouling layer is mainly a mixture of soot and hydrocarbons, formed from deposition of exhaust gases that contain mainly $\mathrm{CO}$, $\mathrm{CO} 2, \mathrm{H} 2 \mathrm{O}, \mathrm{H} 2, \mathrm{CH} 4$, un-burnt hydrocarbons, fine soot particles and nitrogenous compounds. Importantly, the deposit layer is a mixture blend of particulate matter and hydrocarbons that are too difficult to remove from exchanger surfaces.

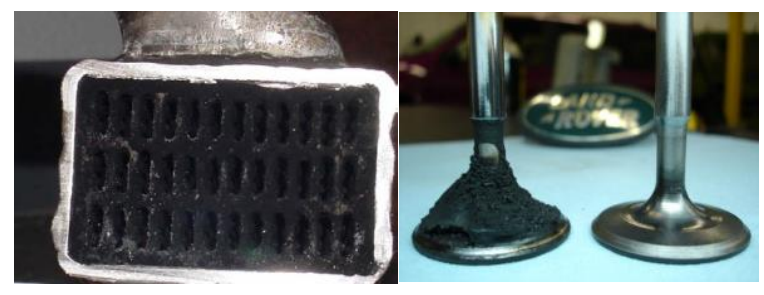

Figure 11-Soot collection

There are four conditions of promoting fouling

a) High concentration of PM at the inlet of the cooler

b) Low gas outlet temperature

c) Wet particles in the exhaust

d) High gas temperature gradient across the cooler

Decreased thermal efficiency is due to its isolating nature and also there is increase in pressure drop due to reduction of the section. The impact has been tested and verified in both engine test benches and recovered vehicles parts. The physical mechanisms forming the fouling layer depend basically on the nature and size of particles in the gas passing the EGR cooler; mainly thermophoresis and inertial impaction are the mechanisms. The finest particles experience a force towards the cooler walls due to temperature gradient between the gas and the wall, much colder. The particles with very low velocity at the surface sticks to the wall forming a thin layer. Larger particles are then trapped by inertial impaction. After some time these fouling layer have asymptotic behavior for EGR Coolers shown in fig \#. The effect on EGR cooler performance is represented by isolation and is characterized by a fouling resistance factor. The fouling resistance is implemented in heat exchanger calculation as an additional thermal resistance for heat flux. Given the heat transfer from the following equation, where total thermal resistance is the inverse of overall heat transfer coefficient (UA), $Q=U \cdot A \cdot \Delta T_{m l}$, with $R_{t}=\frac{1}{U \cdot A}$

the fouling thermal resistance is totalling up to gas side convection, conduction through the wall and coolant side convection.

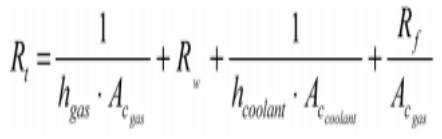

In this latter equation, thermal resistance in gas and coolant side is given by convection coefficient (h), and Rw represents conduction resistance. Fouling resistance is represented by $\mathrm{Rf}$ and the influence of this value on the overall resistance is divided by contact heat transfer area. Magnitude of different thermal resistance results that the most 
important factors are gas side resistance and fouling. In the case of fouling resistance, increased heat transfer area decrease the effect. Thus tubes and fins technology has a lower impact with same value of $\mathrm{Rf}$ that is given by engine operation conditions but the impact on thermal efficiency is very dependent as technologies with more area of heat transfer are less subjected to fouling effect.

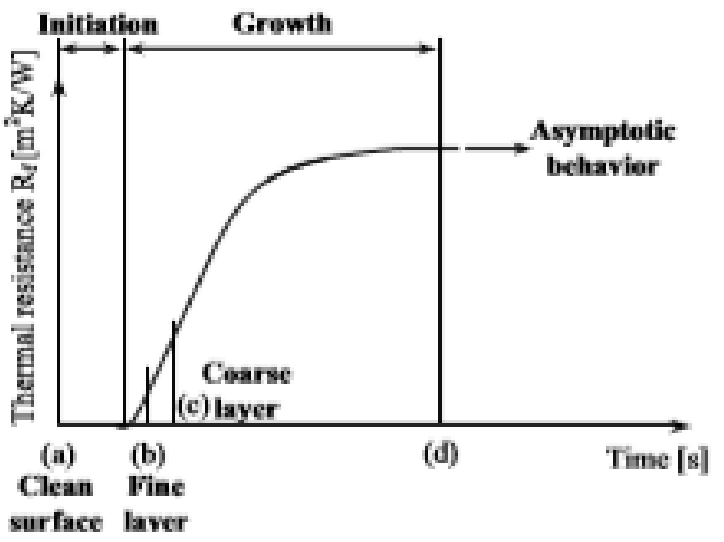

Figure 12- Stages of EGR Fouling

Fouling have a very important uncertainty in design and operation factors of EGR coolers. However, the contribution of fouling mechanism is still unknown though several mitigation techniques have been proposed to minimize.

Increasing the gas velocity in the EGR coolers preventing excessive cooling of the exhaust gases at the beginning of operation and usage of DOC together with DPF seems to reduce particulate fouling. [5][6]

\section{ADVANTAGES OF USING HPL EGR :}

A properly operating EGR can theoretically increase the efficiency of gasoline engines via several mechanisms:

- Reduced throttling losses - Due to the addition of the inert exhaust gases into the intake system, for a given power output, the throttle valve must be opened further, resulting in an increase in inlet manifold pressure and reduced throttling losses.

- Reduced heat rejection - Reduced peak combustion temperatures not only reduces the NOx formation, but it also reduces the loss of thermal energy to combustion chamber surfaces, leaving more energy for conversion to mechanical work during the expansion stroke.

- Reduced chemical dissociation. The lower peak temperatures result in more of the released energy remaining as sensible energy near TDC (Top Dead-Center), rather than being bound up (early in the expansion stroke) in the dissociation of combustion products. This effect is minor compared to the first two.

\section{DISADVANTAGES OF USING HPL EGR :}

EGR decreases the efficiency of gasoline engines via at least one more mechanism:

- Reduced specific heat ratio- A lean intake charge will have a higher specific heat ratio than an EGR mixture. A reduction of specific heat ratio can reduce the amount of energy that can be extracted by the piston

- Since the EGR system recirculates a portion of exhaust gases, over time the valve can become clogged with carbon deposits which can prevent it from operating properly. Clogged 
EGR valves can be cleaned, but has to be replaced if the valve is faulty.

- Though engine manufacturers have refused to release details of the effect of EGR on fuel economy, the EPA regulations of 2002 that led to the introduction of cooled EGR were associated with a $3 \%$ drop in engine efficiency, bucking a trend of a $.5 \%$ a year increase.

\section{FUTURE TRENDS :}

Researches are being made to reduce the amount of NOx emitted by automobiles, especially those using Diesel Engines. There are many techniques available to reduce NOx besides Exhaust Gas Recirculation (EGR) e.g. Retardation of Injection timing, and Selective Catalytic Reduction (SCR) in which EGR is a cheap and easily implemented option. SCR is the most effective technique, but it is currently difficult to implement on present cars and trucks due to the prohibitive cost of the technique and the extensive modification that must be done to the exhaust system. Retarding the injection timing reduces fuel-efficiency and power output and is not favored as it increase soot and $\mathrm{HC}$ emissions. [7]

High HP EGR rates for emission control is been utilized by many advanced combustion concepts under development-for instance low temperature combustion. It is predicted to put more demand on future EGR systems and their components if the application of LTC over a significant portion of the engine operating map becomes mercantile. [1]

In competition to EGR, Urea-SCR aftertreatment will continue to be an alternative NOx reduction technique giving. Depending on the stringency of the respective emission standards, on the progress in NOx conversion efficiency and durability of SCR catalysts, and on the relative costs of diesel fuel and urea. Three main NOx reduction technology pathways can be used in modern diesel engines:[1]

- EGR (without NOx aftertreatment)

- EGR combined with SCR aftertreatment

- SCR only, without EGR

\section{Dual loop EGR systems}

Modern engines run on dual loop EGR systems, which comprises of High pressure EGR system and Low pressure EGR system.

It is seen from studies that the total turbocharger efficiency is the dominant factor determining turbine expansion ratio reduction, and a HPL EGR system gives the lowest expansion ratio.

However, a LPL EGR system creates a lower expansion ratio at EGR percentages lower than $45 \%$, while improving total turbocharger efficiency from $45 \%$ to $48 \%$. This indicates that a LPL EGR system with higher TTE gives lower expansion ratio than a HPL EGR system with low TTE.[8]

It focuses on allowing an engine to run with a LPL EGR system at lower engine speeds, and then switch to a HPL EGR system at engine speeds when the matching point is farther away from the higher efficiency area. For improving engine transient response, this proposed concept relatively enlarges the high efficiency area of a given turbocharger 
and also brings about the possibility for turbocharger downsizing.

\section{CONCLUSIONS}

Emission standards are getting very stringent with every passing year and will only follow a downward trend. Achieving high air quality standards and protecting human health is the primary reason.

High Pressure Exhaust gas recirculation plays a significant role in reducing the engine out Nox emission levels. The use of high EGR rate and the delayed combustion to meet Euro 6 engine-out NOx emission avoid additional aftertreatment and thus having no urea requirement, has lower operating cost, less maintenance and lower vehicle weight, but inherit the drawback of increasing engine BSFC.[9]

But EGR alone would not be sufficient by itself to meet current NOx and PM limits in Europe, Japan and North America. The advances in EGR, Diesel Particulate Filter (DPF), Turbo-Charger (T/C) and fuel injection equipment technology along with aftertreatment technologies like selective catalytic reduction, lean nox trap and diesel particulate filters are required to achive the emisison standards of the future.

\section{REFERENCES}

1. Magdi K. Khair, Hannu Jääskeläinen(2014, Sep). Exhaust Gas Recirculation. [Online]. Available FTP: https://www.dieselnet.com/tech/engine_egr.php [2015, Nov 9]

2. Yunyoung Kim, Cheolmin Park, Jonghyuk Kim, and Byeongdu (2013, Oct 14). The Effect of Low Temperature EGR and Low Compression Ratio on NOx Reduction for EU6 Diesel Engine [Online]. Available FTP: http://digitallibrary.sae.org. File:2013-01-2644 [2015, Nov 11]

3. J Barman (2013, Sep 24). Effective Use of EGR Rate to Reduce NOx and Soot using Multiple Injections in Light Commercial Diesel Engines [Online]. Available FTP: http://digitallibrary.sae.org. File: 2013-01-2424 [2015, Nov 9]

4. https://en.wikipedia.org/

5. J. Lujan and A. Tiseira. (2013, April 8). Characterization of EGR Cooler Response for a Range of Engine Conditions.[Online] Available FTP: http://digitallibrary.sae.org. File: 2013-01-1717 [2015, Nov 9]

6. M.S.A. Elhady, M.R. Malayeri and H.M. Steinhagen. (2009, June 14-19). Fouling problems in exhaust gas recirculation coolers in the automotive industry. [Online] Available FTP: http://heatexchanger-fouling.com/papers/papers2009/17_Malayer_EGR_F.pdf [2015, Nov 29]

7. A. Krishnan, V. C. Sekar, Balaji J, S.M Boopathi. (2006, March 18) Prediction of NOx reduction with Exhaust Gas Recirculation using the Flame Temperature Correlation Technique. [Online]. Available FTP: Proceedings of the National Conference on Advances in Mechanical Engineering http://www.cims.nyu.edu/ arjun/wordpress/wp-content/uploads/EGR_03_06.pdf [2015, Nov 9]

8. L. Zhong, M. Musial, R. Reese and G. Black. (2013, April 8). EGR Systems Evaluation in Turbocharged Engines. [online]. Available FTP: http://digitallibrary.sae.org. File: 2013-01-0936 [2015, Nov 9] 
9. A Panesar, R Morgan, N Miché, and M Heikal. (2013, Sept 8). An Assessment of the Bottoming Cycle Operating Conditions for a High EGR Rate Engine at Euro VI NOx Emissions [online]. Available FTP http://digitallibrary.sae.org. File: 2013-24-0089 [2015, Nov 9]

\section{ABBREVIATIONS}

NOx - Nitrogen Oxide

PM - Particulate Matter

CO - Carbon Mono-Oxide

HC - Hydro Carbon

HPL- High Pressure Loop

LPL- Low Pressure Loop

SCR- Selective Catalyst Reduction

EGR- Exhaust Gas Recirculation

TTE- Total Turbocharger Efficiency, \%

O2- Oxygen

T- Temperature

DPF- Diesel Particulate Filter 